\title{
Se mennesket
}

\author{
- Dyktige leger har en interesse for mennesker som ikke er ulik antropologens, sier Kristian \\ Heggenhougen, norskamerikaneren som ble verdensstjerne i medisinsk antropologi. - Klini- \\ keren er ikke kun tekniker, hun må forstå pasienten som menneske, forstå hva slags liv han \\ lever og hvordan han tenker. Hvis leger er blinde for at helse og sykdom er innvevet i folks kom- \\ plekse liv og påvirkes av hvordan man oppfatter verden, så reduserer de seg selv til mekanikere.
}

Professor Harald Kristian Heggenhougen, Kristian eller bare Kris blant venner, stiller til intervju i det som kanskje er typisk amerikansk østkyst-akademisk stil - velbrukt dressjakke av god kvalitet, en myk skjorte som ligger lunt mot kroppen, romslige bukser. Rundt halsen under skjegget henger avviket - et grønt designerskjerf av ull, tydelig preget av opphavsmannens smak og tekniske kompetanse. - Det har jeg fått av mitt åtte år gamle barnebarn, er han ikke flink? sier Kristian stolt. Vi benker oss i en øde formiddagsrestaurant $\mathrm{i}$ Bergen og tar stoisk for oss av det som viser seg å være stedets mikrobølgeoppvarmede lunsjmeny uten preg av noe som helst. Men dette er en mann som har smakt verre, selv om han senere innrømmer at han kanskje ikke er den erketypiske antropolog tross alt - han klarte aldri å forsone seg med masaienes kosthold av varm melk og blod rett fra dyrets hals.

- Jeg har vært barn mange ganger og mange steder, jeg har følt meg liten og uvitende. Å være antropolog handler om å vandre $\mathrm{i}$ andres verdener, så lenge og så langt inn i det hverdagslige at man ender med å kjenne seg hjemme der. Hvis du virkelig skal komme inn hos menneskene du vil forstå, må du legge fra deg din voksenhet ved døren og la dem lære deg hvordan det er å være menneske der. Jeg er den evig fremmede som er hjemme overalt og ingensteds. Å tilpasse seg har vært nødvendig, og jeg har lykkes ganske godt med det. Noen ganger tenker jeg at det er farlig. Man kan bli moralsk relativist. Bør man tilpasse seg normer man egentlig er uenig i? Hvordan skal du tenke hvis du glir inn i et samfunn hvor barnearbeid er naturlig? Eller et sted hvor kvinners kår er elendige? Man kan bli dradd med, man får jo øye på den indre logikken og fornuften i slike ordninger. Jeg har vært bekymret for å ende opp som total kulturrelativist, en slik som sier «Hitler? Ja han hadde jo sin virkelighetsforståelse.»

\section{Hjemkomst og vennskap}

Til sin forundring har Kristian Heggenhougen vendt hjem til Norge fra en lang karriere ved verdens fremste universiteter. I 2000 lot han seg lokke til å undervise enkeltkurs ved Senter for internasjonal helse (SIH) ved Universitetet i Bergen. Her slo han rot - i den grad nomader slår rot. En vakker kvinne og et varmt fagmiljø ble utslagsgivende. - Jeg holder kurs for fremragende studenter fra allverdens land, akkurat nå fra Makedonia, India, Iran, Italia, Sudan, Belgia, Tyskland, Kosovo, Norge osv., det er så flott! forteller han. Helse, politikk og rettferdighet er stikkord for undervisningen. Instituttleder Rune Nilsen skriver: «For SIH har Kristian vært av uvurderlig betydning. Han er en forsker som beveger seg i faggrensene, alltid interessert i kunnskap fra dem han møter. Han har alltid denne sammen-

\section{«Jeg kan sammenlikne, jeg kan se ulikhetene, men også hvordan felles menneskelige fenomener gis form i forskjellige verdener»}

hengen rundt det han reflekterer om. Hans grunnleggende etiske fundament er så tydelig i fagligheten, men også i hans væremåte med kollegaer og studenter. Han formidler som en gud, med humor og innlevelse, med tyngde og autoritet som alltid viser brei åpenhet faglig, alltid med et perspektiv på fattigdom og sosial rettferdighet. Han er en fantastisk personlighet som er mer opptatt av andres styrke enn sin egen. I min heimbygd ville de brukt ordet «finsleg», det sier mye om ham.»

\section{Nomaden}

Kristian var gutten som ville se hva som fantes bak åsen, rundt neste sving. Hans eget liv ble en klassereise fra kontinent til kontinent. Han ble født på Notodden i krigsdagene våren 1940, mens tyske soldater var på vei fra Oslo til Kongsberg for å ta kontrollen på Norsk Hydro hvor faren var direktør. Faren heiste flagget i glede over gutten, men måtte fort fire det igjen for ikke å bli misforstått. I 1954 ble foreldrene skilt, Kristian og lillesøster fulgte mor på Amerika-båten. Det ble farvel til hjemlandet, til faren, til en privilegert sosial posisjon med bokhyller og god økonomi. Mor giftet seg med en norskamerikansk melkemann i New Jersey. Kristian ble gutten som holdt familiens mot oppe, som støttet mor og passet på søster i trange kår. At han skulle bli professor på Harvard lå ikke i kortene.

Etter collegeeksamen i 1962 bygde den unge studenten hus et halvt års tid, tjente noen dollar og haiket tvers over USA.

I Mexico lærte han seg spansk og ble hanket inn som statist $i$ en stor amerikansk spillefilm. En norsk båt ga ham skyss til Peru, mot maling og rustbanking. Han bodde noen måneder blant Quechua-folket 4000 moh. før han reiste til Chile i ett år, videre til Argentina og Uruguay og endte opp i Rio de Janeiro til karnevalets 400-årsfest. Først i 1965 kom han tilbake til USA, fikk seg jobb på Manhattan og begynte å studere ved New School for Social Research, en intellektuell trykkoker dominert av fremstående jødiske akademikere som hadde flyktet fra Europa under jødeforfølgelsene, blant dem samfunnsfilosofene Hans Jonas og Hannah Arendt. Her tok Kristian sin mastergrad i sosiologi. Så fulgte studier i antropologi og feltarbeid blant mayafolk i Guatemala. Helse, sosial nød og lidelsen som skyldes strukturell vold i samfunnet, ble sentrale faglige og menneskelige stikkord. På slutten av 1970-årene fikk han postdokstipend fra University of California og jobbet tre år med tradisjonell medisin og helseforståelse i Penang i Malaysia hvor han lærte malayspråket. Gjennom 1980-årene underviste og forsket han ved London School of Hygiene and Tropical Medicine og gjorde nye feltstudier, denne gang i Tanzania, hvor språket var swahili. 


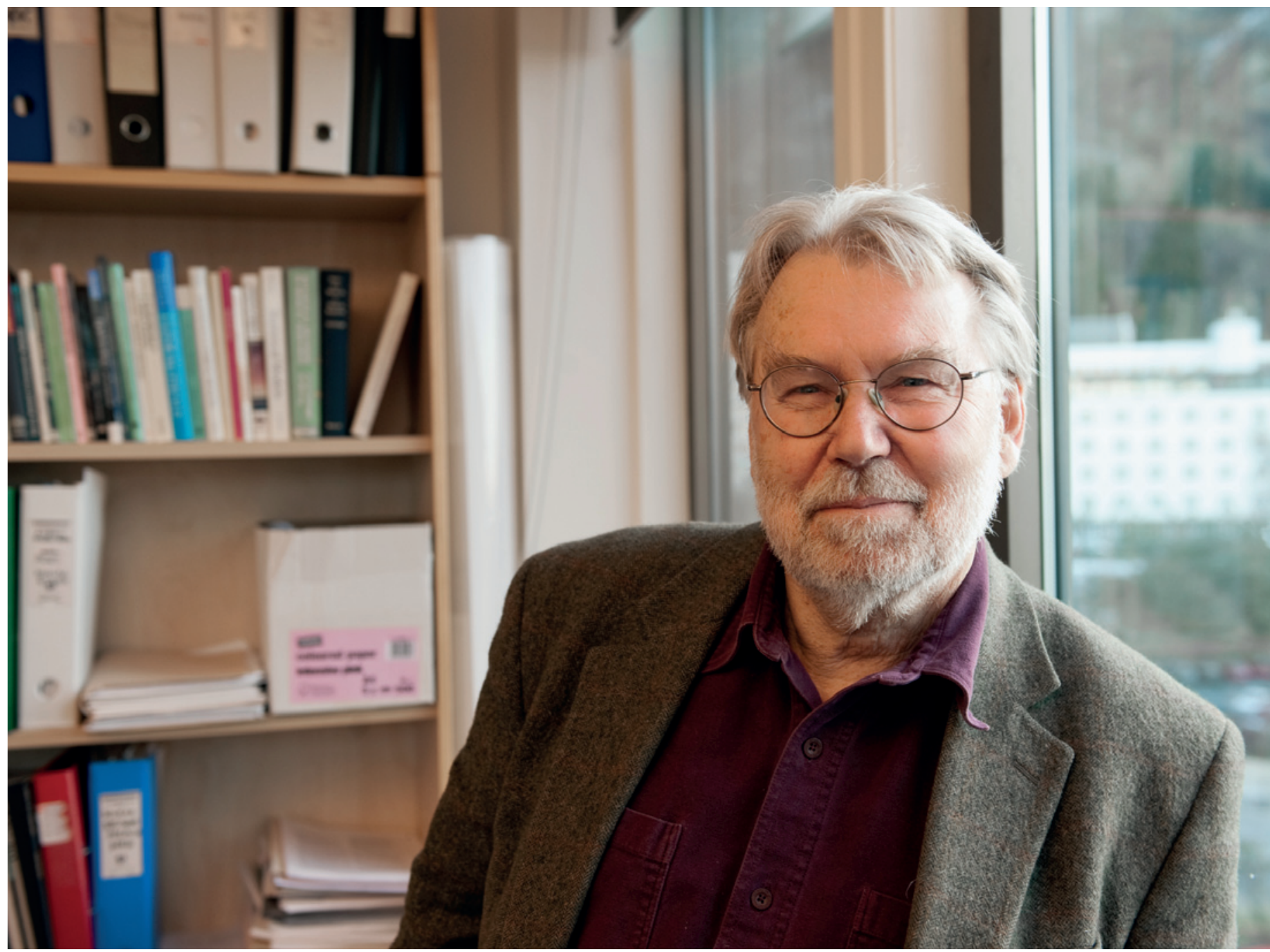

Foto Scanpix

\section{Harald Kristian}

\section{Heggenhougen}

Født 24.4. 1940

- Emigrerte 14 år gammel fra Oslo til USA

- Sosiolog og antropolog. Feltarbeid i Latin-Amerika, Asia og Afrika

- Underviser ved London School of Hygiene and Tropical Medicine 1979-89

- Associate professor ved Harvard University, Department of Social Medicine 1989-2000

- Professor ved Boston University, Department of International Health 2000-07

- Professor II ved Senter for internasjonal helse, Universitetet I Bergen 2000 -

- Ansvarlig redaktør for International Encyclopedia of Public Health, 5000 sider i seks bind, med mer enn 950 forfattere 2008 -

\section{Stedets filosofi}

- Noen antropologer lever et faglig liv i dybden, de studerer sitt samfunn i tiår etter tiår og trenger virkelig dypt inn. Jeg kan misunne dem det. Min styrke er som komparativ antropolog. Jeg kan sammenlikne, jeg kan se ulikhetene, men også hvordan felles menneskelige fenomener gis form i forskjellige verdener. Trass i kulturforskjeller er jo de grunnleggende ting felles for oss mennesker, særlig når det kommer til følelser og relasjoner, sorg og lykke. Det er derfor man kan få denne hjemfølelsen i de merkeligste miljøer. Det har vært viktig for meg å bli fortrolig med det fremmede. Slik får jeg to øyne, jeg ser også det kjente på en mer kritisk måte. Man forstår ikke hva «sted» betyr hvis man bare kjenner sitt eget. Da tror man det lokale er universelt, at mennesker «egentlig» er og bør være slik de er hos oss. Slik provinsialisme skaper alltid et potensial for fremmedfrykt, forakt og aggresjon.

\section{Antropologer og leger}

- En kulturkløft du kjenner godt er den mellom leger og samfunnsforskere. Har leger bruk for antropologens kunnskap? Har du opplevd leger som interesserte?

- Leger lager lett et skille mellom teknisk kompetanse, som å kunne spinalpunktere, og forståelseskompetanse, som skjer i språket, i tenkning, i relasjoner. Jeg har undervist svært mange legestudenter og leger. Om de har fått med seg noe fra den undervisningen? De protesterte ikke, men jeg er ikke sikker på hvor mye som ble sittende igjen. Det er jo kirurgi og håndverk som er «the real stuff»» i legers mytologi, som gir retning til identitetsdannelsen, til tenkningen. Alle vil jo være «ekte» i det de oppfatter som sin egen kultur. Og da faller vi lett utenfor, vi som driver med forståelse og kultur. Som han sa legen jeg jobbet med ved London School of Hygiene: «Oh, anthropology, jolly good! As long as it doesn't get in the way of the real stuff, of course.» 
Det er synd, for leger trenger det antropologer kan. Klinikeren er antropolog, han må forstå mer enn det tekniske, han må forstå mennesket han vil hjelpe, først og fremst forstå hva pasienten forstår, som filosofen Kierkegaard påpekte. Hvis leger er blinde for at helse og sykdom er innvevet i folks komplekse liv og påvirkes av hvordan man tenker om verden, så reduserer de seg selv til mekanikere. Jobber du i katastrofeområder med 90 pasienter om dagen, har du knapt noe valg, men det er jo ikke ideelt, for å si det mildt. Leger i vår tid er opplært til å høre, men først og fremst til å gjøre. Men «gjøringen» blir mye bedre om man først hører godt og profesjonelt - så man forstår hva den andre forstår.

\section{Stereotypier}

I 1989 ble Heggenhougen invitert til Harvard av en berømt medisinsk antropolog, Arthur Kleinman, som også er psykiater. Kleinman er en kontroversiell person, kjent for stadig å havne i konflikt, men om Heggenhougen har han sagt: «Kris is like a grassy hillside in the sunshine.» Kleinman har vært opptatt av sykdommers sosiale formbarhet, han viste i 1970-årene at personer i asiatiske kulturer tenderer til å uttrykke konflikt og lidelse gjennom somatiske symptomer, mens vestlige mennesker uttrykker det samme gjennom psykisk lidelse. Jeg spør min Harvard-antropolog: Hvor mye vet vi om et menneske når vi kjenner dets nasjonalitet, språk og etnisitet?

- Kulturelle stereotypier finnes, og kan være interessante, sier Heggenhougen mens han titter tålmodig gjennom brilleglassene. - Det er lett å snakke i klisjeer om folk, men jeg liker det ikke. Japanere klarer mer smerte, italienere mindre. Men om du på fødeavdelingen hører en kvinne hyle og avfeier henne med at «hun er bare italiensk»», hva foregår da? Forskjellene innad i en gruppe er stort sett større enn forskjellene mellom en gruppe og en annen. Det er større kulturell spredning mellom samer i Kautokeino enn det er kulturforskjeller mellom samer og nordmenn. Jeg kunne si at jeg egentlig ikke liker mennesker, jeg liker bare Jagdish, Nina, Astrid. Mennesker er individer, og vi roter det til når vi tenker på dem i klynger og kategorier, slik vi jo gjør. Når du hører om en mor på Haiti som ikke tar sin aidssyke gutt til legen, er det da latskap, typisk Haiti? Eller er det at hun er fattig med mange å holde i live, har tre jobber og ingen mann, kan ikke klare å få gutten til lege uten å miste jobbene sine? Culture is not everything!

\section{Det norske}

- Du som har brukt hele ditt liv til å se det kjente med fremmede øyne, du kan kanskje se oss nordmenn klarere enn vi ser oss selv? Finnes det en norsk kultur?
- Nå har jeg prøvd å si at unntakene er mange og viktige, det finnes alltid moteksempler. Men jeg tenker nok at vi ofte er provinsielle i Norge også, ikke bedre enn amerikanerne når vi synes vi skjønner ting best $\mathrm{og}$ har de rette svarene. Selvgodheten merket jeg i Afrika da jeg møtte ambassadefolk som skulle støtte norsk aidsforskning. Jeg tilbød dem faglig kontakt med lokale forskere. Det brydde de seg ikke om, og det skuffet meg. På den annen side... Han slår sjenerøst ut med armen. - Det er mye godt å si om Norge og norsk mentalitet.

Mange av oss har blikket vendt mot verden, de fleste snakker jo minst to språk. Jeg snakket spansk med min 95 år gamle tante - hun var pensjonert sekretær - for at vi begge skulle holde språket ved like. De norske «sydenturene» er ikke akkurat dannelsesreiser, men til gjengjeld er det utrolig mange nordmenn som har studert i utlandet, arbeidet der, eller reist til sjøs og sett verden den gang lille Norge hadde verdens tredje største handelsflåte. Min morfar reiste jorden rundt sju ganger på seilskip, jeg ble nok inspirert av hans fantastiske fortellinger

Norge blir hver dag mer multikulturelt, ikke uten problemer, men det skurer også bort provinsialiteten. To tanzanianske damer satt på trikken i Oslo og snakket ufint om medpassasjerene, på kiChaggaspråket. En ung blond dame reiste seg og hvisket i forbifarten på perfekt kiChagga at det ikke var bra å uttale seg så negativt og høylytt om andre. Slikt er morsomt.

Nordmenn er nokså ærlige, det er mye tillit mellom oss. Og vi har en kultur som tross alt holder personlig beskjedenhet høyt, slik janteloven illustrerer. Det motvirker hybris. Men det kan også hindre nordmenn i å få start på sin egen motor. Det går en historie om den norske antropologen som bodde mange år i Kina, lærte seg perfekt mandarin og tre lokale språk, kjente alle skikkene, hadde et stort nettverk. Han kom hjem til Norge og syntes ikke han visste så mye om Kina. Hans amerikanske kollega reiste tre dager i landet og skrev bok om det - China today, yesterday and tomorrow...

\section{Vennskap}

Mange vil gjerne uttale seg om professor Heggenhougen, og de har noe felles i tonefallet, det likner kjærlighetserklæringer: «Ja! Jeg vil gjerne fortelle om Kristian, om å ha språket i sin makt, om engasjementet, om forholdet til studentene, om den spesielle undervisningsformen(!), om dansen, om de globale festene, om gourmetkokken, om et nydelig menneske,» skriver en norsk kollega. Og Carola Eisenberg, fremtredende psykiater på Harvard, tidligere Dean of students ved både Harvard Medical School og Massachusetts Institute of Technology, nå vel over nitti, svarer på e-post: «He was always warm, had a sense of humor and related extremely well to these young students. As a friend I found him to be loyal, devoted, responsive and charming. Whenever he visited the Boston area, he always came to visit me with a big bunch of blue Irises that delighted me.»

Paul Farmer, legen, antropologen og helteskikkelsen som grunnla Partners in Health og leder Harvard Medical School's Department of Global Health and Social Medicine mens han bor i Rwanda og er FNs spesialutsending til Haiti (en heseblesende presentasjon gjenspeiler mannens heseblesende liv), fant tid til å skrive om sin venn og lærer: «I first met Kris through his work, but have been lucky enough to be his colleague and friend for the past two decades. It's hard to think of anyone else on the planet who has done serious long-term fieldwork on three continents, and harder still to think of anyone else who has worked so diligently to translate ethnographic understanding and social theory into tools of interest to public health and medicine. He has made great and enduring contributions to public health, anthropology, and medicine.»

\section{There is a crack}

«There is a crack in everything, that's how the light gets in,» synger Leonard Cohen. Kristian Heggenhougen ser ikke på seg selv som spesielt vellykket, han er påfallende lite arrogant for en mann med en CV på 35 sider. - Jeg er nesten alltid i tvil om jeg gjør det rette, om jeg bor i riktig land, hva jeg skal bli når jeg blir stor... Han smiler trist. - Jeg blir lett nervøs, er ikke så fornøyd med meg selv. Det føles som en forbannelse, en nisse som har sittet på lasset uansett hvor jeg har reist i verden. Jeg som lever av å forstå mennesker forstår ikke meg selv.

Kristians beste venn er Jagdish, UNESCO-professor ved University of London. Han bekrefter denne várheten: «Kris er det vennligste menneske man kan møte i et akademisk elitemiljø, han har en respekt for andres perspektiv som alltid har gitt dybde til hans tenkning. Han er konstant spørrende, som en vitenskapsmann skal være. Men det gjør også at han alltid er bekymret for alt mulig. Et vidunderlig sammensatt menneske! Han elsker å stå på scenen, skuespillertalentet gjør ham til en feiret underviser. Han kjører bil altfor fort, han har stor humor, han er en sarkastiker og festløve som kan danse hele natten. It is wonderful to have a friend like him.»

\section{Edvin Schei}

edvin.schei@isf.uib.no

Seksjon for allmennmedisin

Universitetet i Bergen 